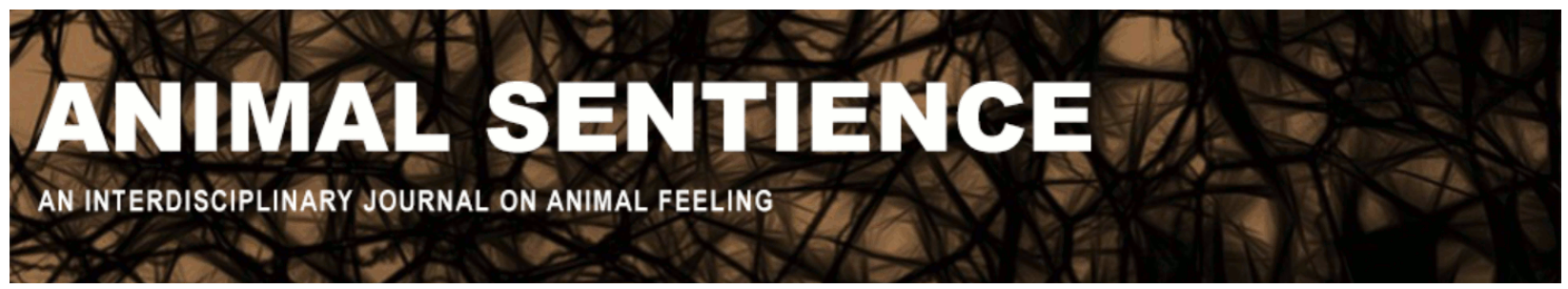

Mallatt, Jon and Feinberg, Todd E. (2017) Consciousness is not inherent in but emergent from life. Animal Sentience 11(15)

DOI: $10.51291 / 2377-7478.1204$

Date of submission: 2017-05-22

Date of acceptance: 2017-05-28

(c)

This article has appeared in the journal Animal

Sentience, a peer-reviewed journal on animal

cognition and feeling. It has been made open access,

free for all, by WellBeing International and deposited

in the WBI Studies Repository. For more information,

please contact

wbisr-info@wellbeingintl.org.

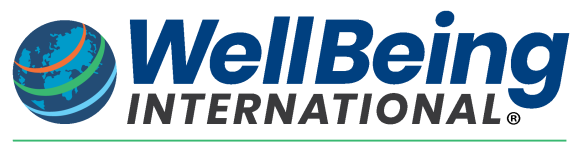

SOLUTIONS FOR PEOPLE, ANIMALS AND ENVIRONMENT 


\title{
Consciousness is not inherent in but emergent from life
}

Commentary on Reber on Origins of Mind

\author{
Jon Mallatt \\ WWAMI Medical Education Program \\ University of Idaho \\ Todd E. Feinberg \\ Psychiatry and Neurology \\ Icahn School of Medicine at Mount Sinai
}

\begin{abstract}
Reber's theory of the cellular basis of consciousness $(C B C)$ is right to emphasize that we should study consciousness (sentience) in its simplest form, taking its evolution into account. However, not enough evidence is presented to support $\mathrm{CBC}^{\prime}$ 's unorthodox claim that even simple, one-celled organisms are conscious. As pointed out by other commentators, the $C B C$ seems to be based on outdated ideas about evolution and does not acknowledge that consciousness could be an evolutionary novel feature. Such emergent features are abundant in living organisms. We review our own emergentist solution, in which consciousness evolved in the elaborating nervous systems of the first vertebrates and arthropods.
\end{abstract}

Keywords: cellular basis of consciousness, origin of consciousness, emergence, systems theory, evolution, neurobiological naturalism, bacteria

Jon M. Mallatt is Clinical Associate Professor in the WWAMI Medical Education Program of the University of Washington at the University of Idaho. His research is on the origin of the major animal groups, especially vertebrates. He has worked with Todd Feinberg on the origin and nature of consciousness since 2013.

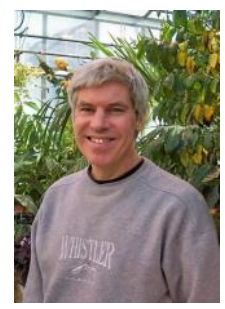

Todd E. Feinberg, Clinical Professor of Psychiatry and Neurology in the Icahn School of Medicine at Mount Sinai, is internationally recognized as a leading authority on how the neurobiology of the brain creates the individual's sense of identity. http://www.toddfeinberg.com

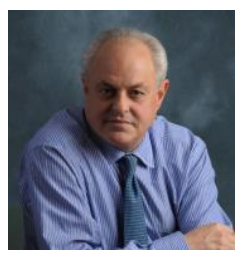

This commentary discusses Reber's (2016a) original target article about his theory of the cellular basis of consciousness ( $C B C$ ) as well as the commentaries and the author's responses to them (Reber, 2016b, 2017) that have appeared so far. The CBC theory says consciousness is not a product of nervous systems (contrary to the standard view), but is a basic feature of life and accompanies even the simplest life forms such as bacteria. 
We understand what Reber was striving to do with this theory: to reduce the baffling hard problem of consciousness to an easier problem that can be investigated empirically with known, scientific techniques. This easier problem would be to find the biochemical mechanisms that give bacteria sensitivity to outside stimuli and let them approach or recoil upon "experiencing" a stimulus as good or bad. Several of the other commentators (Ball, 2016; Brakel, 2016; Broude, 2016; Woodruff, 2016) questioned this strategy, but we feel the author explained and defended it well as a mechanistic rebuttal of dualism (Reber, 2016b, p. 5; 2017, p. 3). We also like his refutation of panpsychic theories of consciousness: "if sentience is everywhere it might as well be nowhere for it will be impossible to ascertain either existence or nonexistence" (2016b, p. 3). Like some of the other commentators, we laud his evolution-centered, bottom-up approach (Ball, 2016; Morsella \& Reyes, 2016; Ristau, 2016) as an important counterbalance to the great majority of consciousness studies that only investigate the human cerebral cortex (e.g., Gutfreund, 2017).

Our problem, however, is with CBC's basic claim that one-celled organisms with no nervous system are conscious. Too little evidence is given to support such an iconoclastic claim. One might say that some evidence was presented, this evidence being that even the simplest life-forms respond and react to stimuli. But this is not enough because nonconscious neural reflexes demonstrably do these same things, despite being more complex than bacteria (also see the commentaries of Morsella \& Reyes, 2016, and Safina, 2016). In science, extraordinary claims - like bacterial consciousness - require extraordinary evidence, meaning abundant evidence systematically applied (Sagan, 1980). It is not valid to present the claim as an axiom and then deem it correct because it seems to fit evolutionary principles and seems to give better solutions to thorny philosophical problems (e.g., to the difficulties of the hard problem and the “Emergentist's Dilemma").

Skipping the primary evidence is especially inappropriate here because much is known about how bacteria receive and respond to stimuli. But Reber did not cite a single study on this, neither in 1997 when first proposing the CBC, nor two decades later in his 2016 paper, by which time the relevant information had grown markedly (Reber, 1997, 2016a). In fact, commentators Woodruff (2016) and Safina (2016) had to introduce this literature. Once its richness became evident to us, we easily found more of it: see Booth (2014); Brohawn et al. (2014); and Sourjik \& Wingreen (2012). Assuming an axiom without having considered the available evidence is not how science is done. Safina squarely criticized this no-evidence approach, and Reber's (2017) dismissal in response is discouraging: "I am not a molecular biologist and have no solution to the question of how subjectivity is created in single-cell organisms. I merely claim that it is so created." No, the burden of proof is on Reber as the claimant to find and master the scientific literature pertaining to his claim. Even philosophers can read science papers or consult a scientist.

We agree with most of the criticisms in the commentary by Key (2016), who shares the standard view that consciousness needs a nervous system. ${ }^{1}$ To us, it really does seem that Reber is claiming that this standard, neural-computational, view makes consciousness too difficult to understand, so his approach is needed because it is easier ("far more tractable": 2016a, pp. 7-8). On the contrary, as Key points out, if a problem is difficult and the answer is currently unknown, it does not follow that it is unsolvable or that current modes of inquiry have met a dead end. More on this below. 
Second, as Key indicates, the evolutionary principles used to build the CBC do not seem correct. These principles appear to presuppose that evolution proceeds in a straight line from simple to complex as if directed up a pyramid. ${ }^{2}$ Some of them seem to precede the "modern evolutionary synthesis" of the 1930s and 1940s. An entry in the literature on current evolutionary ideas is provided by Laland et al. (2014).

Third, Key points out that important new features evolve in biological lineages over time (fins in fish, milk in mammals, and many more: Peterson \& Muller, 2016); Reber's target article does not show an appreciation of this. Key's implication is that consciousness could easily be one of these evolutionary innovations. Then Broude (2016) states this point explicitly. We view Key's and Broude's criticism of Reber's target article as correct, because Reber says little about novelty but instead states that the core or rudimentary aspects of later-evolved features are there from the start and "what gets added isn't ontologically novel; it's a gradual accretion of functions" (Reber, 2016a, pp. 4-5). Consciousness as an evolutionary novelty would be absolutely devastating to Reber's theory, according to which it would have to have been present from the start of life. Reber's reply to the no-novelty criticism is odd: he states that he does allow evolutionary novelty, as exemplified by his former theory about the unconscious (?) (2016b, p. 4); and he admits that pre-existing consciousness evolved new features to become more complex $(2017$, p. 3). But he never allows that consciousness itself is a novelty, so he does not address the criticism.

As stated above, Reber objects to the standard theory that consciousness requires a nervous system because he feels that theory leads to thorny difficulties. More important, he objects because the standard theory seems to demand an impossible origin for consciousness: "It requires that at some moment in evolutionary history a capacity for subjective representation blinked into ontogenetic reality whereas one cosmic moment before no species possessed it" (2016b, p. 4; 2016a, p. 7). He calls this impossibility the "Emergentist's Dilemma." But a consideration of the true property of emergence - the emergence that characterizes all complex biological systems - eliminates any such problem. In systems theory (Ahl \& Allen, 1996; Salthe, 1985; Simon, 1962, 1973; Feinberg, 2011), life and the biosphere are recognized as being arranged hierarchically into many levels of increasing complexity with new properties arising (emerging), from lower properties, at each higher level. For example, biomolecules like DNA and proteins emerge from simpler molecules and atoms, cell organelles emerge from the biomolecules, and the living cell from the organelles. Consciousness is no different in principle, emerging anew from high levels of neural processing. ${ }^{3}$ The new, emergent properties all arose over evolutionary time and none are unexplainable miracles.

The emergent property of life itself, which was considered a mystery and a miracle throughout most of human history, is especially informative about consciousness. If Reber (and Velmans, 2016) were to apply their non-emergent arguments to life, they would have to say life could not have evolved step-by-step because it could not have blinked into existence instantaneously from a nonliving entity. They would accordingly have to conclude that life is inherent in lower levels of organization, which here would mean life is in DNA or even in atoms. But this reasoning leads to a strange animism (living molecules!) that no modern scientist would accept, so it is dubious. Our point is that consciousness is an emergent feature of complex hierarchical systems, as is life. Scientists just understand more of the steps in the evolution of life than in the evolution of consciousness, so the latter seems a mystery. That is, we say life is 
on the "it's difficult but we can solve it" side of a line and consciousness is on the "it's so difficult that it's hard even to even see how to solve it" side of the same line. If this is the correct way to view things, then the rapidly growing body of neurobiological knowledge bodes well for solving more difficulties of consciousness in the future. Despite science's still-incomplete understanding of life and how it evolved (Ruiz-Mirazo et al., 2014), life is not considered a mystery; so, by analogy, consciousness should not be either.

Our own theory of the origin of consciousness is called neurobiological naturalism. In constructing this theory, we pondered which set of neural features led to the emergence of consciousness (Feinberg \& Mallatt, 2016a, 2016b) and then deduced that it originated in the first vertebrate fish and the first arthropods between 560 and 520 million years ago in the Cambrian Period. Fossil evidence from this age documents the rapid evolutionary elaboration of sensory organs, nervous systems, behaviors, and indirectly, cognition (Carbone \& Narbonne, 2014; Erwin \& Valentine, 2013; Trestman, 2013). In our emergentist approach to the evolution of consciousness during that time, we related consciousness to the first appearance in brains of mapped, mental simulations of the world and of the first affects ("emotions"), all of which helped the conscious animals to target their interactions with the world. There is much more to this argument, so the reader is directed to our publications and to the similar theory of Klein and Barron (2016). We do not know exactly how long it took for vertebrates and arthropods to go from nonconscious to conscious in the Cambrian (several million years?), just as no one knows exactly how long it took for life to evolve from non-life almost four billion years ago. However, we are confident that both consciousness and life - and all the myriad emergent properties of living systems - evolved continuously and without any breaks that demand miracles to fill.

We recognize three emergent revolutions in the continuous path from matter to consciousness. First was the evolution of life itself, with all of life's attendant, uniquely biological features (Mayr, 2004). Second, about 580 million years ago some Precambrian animals evolved nervous systems with reflexes, which allowed unique and even complex neural processing but did not require consciousness. Third, in the Cambrian, came consciousness when complex brains with multi-level, reciprocally arranged neural hierarchies and specialized neurons allowed the emergence of conscious mapped images and affects (Feinberg \& Mallatt, 2013, 2016a, 2016b).

In summary, we used an evidence-based argument to reach a conclusion different from the $\mathrm{CBC}$. Consciousness is not inherent in life but an emergent property of complex nervous systems. We challenge the $\mathrm{CBC}$ to provide more up-to-date biological evidence for its axiom.

\section{Footnotes}

\footnotetext{
${ }^{1}$ We do not agree, however, with Key's view that consciousness needs a cerebral cortex as in mammals.

${ }^{2}$ Reber's principles seem to contain claims with which today's evolutionary biologists would disagree: "Mutations . . . tend to occur in the upper layers [i.e., in later-evolving features] not in the core, foundational form [in features that evolved earlier]" (2016b, p. 4); and "Adaptive forms and functions are not jettisoned [i.e., no traits are ever lost throughout evolutionary history]" (2016a, p. 4).

${ }^{3}$ Because we have demanded that claims be supported by evidence, here are two pieces of evidence that consciousness is an emergent property of complex nervous systems: (1) the brain is more complex than a cell; (2) damage to the human cerebral cortex interferes with consciousness (Feinberg, 2009).
} 


\section{References}

Ahl, V., \& Allen, T. F. (1996). Hierarchy Theory: A Vision, Vocabulary, and Epistemology. New York: Columbia University Press.

Ball, D. (2016). No help on the hard problem. Animal Sentience 11(8)

Booth, I. R. (2014). Bacterial mechanosensitive channels: Progress towards an understanding of their roles in cell physiology. Current Opinion in Microbiology, 18, 16-22.

Brakel, L. A. W. (2016). Mind/body "hard problem" is not a category error. Animal Sentience $11(3)$

Brohawn, S. G., Su, Z., \& MacKinnon, R. (2014). Mechanosensitivity is mediated directly by the lipid membrane in TRAAK and TREK1 K+ channels. Proceedings of the National Academy of Sciences, 111, 3614-3619.

Broude, G. J. (2016). Still wondering how flesh can feel. Animal Sentience 11(13)

Carbone, C., \& Narbonne, G. M. (2014). When life got smart: The evolution of behavioral complexity through the Ediacaran and early Cambrian of NW Canada. Journal of Paleontology, 88, 309-330.

Erwin, D. H., \& Valentine, J. W. (2013). The Cambrian Explosion. Greenwood Village, CO: Roberts and Company.

Feinberg, T. E. (2009). From Axons to Identity: Neurological Explorations of the Nature of the Self (Norton Series on Interpersonal Neurobiology). New York: WW Norton \& Company.

Feinberg, T. E. (2011). The nested neural hierarchy and the self. Consciousness and Cognition, 20, 4-15.

Feinberg, T. E., \& Mallatt, J. (2013). The evolutionary and genetic origins of consciousness in the Cambrian Period over 500 million years ago. Frontiers in Psychology, 4, 667.

Feinberg, T. E., \& Mallatt, J. (2016a). The nature of primary consciousness. A new synthesis. Consciousness and Cognition, 43, 113-127.

Feinberg, T. E., \& Mallatt, J. M. (2016b). The Ancient Origins of Consciousness: How the Brain Created Experience. Cambridge, MA: MIT Press.

Gutfreund, Y. (2017). The neuroethological paradox of animal consciousness. Trends in Neurosciences, 40, 196-199. 
Key, B. (2016). "Cellular basis of consciousness": Not just radical but wrong. Animal Sentience 11(5)

Klein, C., \& Barron, A. B. (2016). Insect consciousness: Commitments, conflicts and consequences. Animal Sentience 9(21)

Laland, K., Wray, G. A., \& Hoekstra, H. E. (2014). Does evolutionary theory need a rethink? Nature, 514, 161.

Mayr, E. (2004). What Makes Biology Unique? Considerations on the Autonomy of a Scientific Discipline. Cambridge: Cambridge University Press.

Morsella, E., \& Reyes, Z. (2016). The difference between conscious and unconscious brain circuits. Animal Sentience 9(11)

Peterson, T., \& Müller, G. B. (2016). Phenotypic novelty in EvoDevo: The distinction between continuous and discontinuous variation and Its importance in evolutionary theory. Evolutionary Biology, 43, 314-335.

Reber, A. S. (1997). Caterpillars and consciousness. Philosophical Psychology, 10, 437-449.

Reber, A. S. (2016a). Caterpillars, consciousness and the origins of mind. Animal Sentience 11(1)

Reber, A. S. (2016b). Resolving the hard problem and calling for a small miracle. Animal Sentience 11(9)

Reber, A. S. (2017). To identify all the relevant factors is to explain feeling. Animal Sentience $11(14)$

Ristau, C. A. (2016). Beginnings: Physics, sentience and LUCA. Animal Sentience 11(4)

Ruiz-Mirazo, K., Briones, C., \& de la Escosura, A. (2014). Prebiotic systems chemistry: New perspectives for the origins of life. Chemical Reviews, 114, 285-366.

Safina, C. (2016). Reber's caterpillar offers no help. Animal Sentience 11(12)

Sagan, C. (1980). Broca's Brain: Reflections on the Romance of Science. New York: Presidio Press.

Salthe, S. N. (2013). Evolving Hierarchical Systems: Their Structure and Representation. New York: Columbia University Press.

Simon, H. A. (1962). The architecture of complexity. Proceedings of the American Philosophical Society, 106, 467-482. 
Simon, H. A. (1973). The organization of complex systems. In H. H. Pattee (Ed.), Hierarchy Theory: The Challenge of Complex Systems (pp. 1-27). New York: George Braziller.

Sourjik, V., \& Wingreen, N. S. (2012). Responding to chemical gradients: Bacterial chemotaxis. Current Opinion in Cell Biology, 24, 262-268.

Trestman, M. (2013). The Cambrian explosion and the origins of embodied cognition. Biological Theory, 8, 80-92.

Velmans, M. (2016). How could consciousness emerge from adaptive functioning? Animal Sentience 11(6)

Woodruff, M. L. (2016). Bacteria and the cellular basis of consciousness. Animal Sentience 11(2) 